\title{
Some Morphological Characteristics of Porous Polymeric Membranes Prepared by "Micro-Phase Separation Method"
}

\author{
Sei-Ichi Manabe, Yukari Kamata (née Shigemoto), \\ Hideki IJJIMA, and Kenji KAMIDE* \\ Fundamental Research Laboratory of Fibers and Fiber-Forming Polymers, \\ Asahi Chemical Industry Co., Ltd., Takatsuki, Osaka 569, Japan
}

(Received July 12, 1986)

\begin{abstract}
An attempt was made for the micro-porous cellulose and cellulose acetate (CA) membranes prepared by the micro-phase separation method, (1) to evaluate by the electron micrographic (EM) method the pore radius $(r)$ distribution $(N(r))$ of the hypothetical inner layers of the membranes parallel to and apart from the surface by the distance $Z$ and (2) to explain the morphological characteristics of these membranes by the particle-growth theory presented previously by Kamide and Manabe, taking into consideration the development of the phase separation of the solution during casting process. For this purpose, the cloud point curve and the binodal (the compositions of two coexisting phases at equilibrium) were determined for the cuprammonium solution giving the cellulose membranes. Transport phenomena of ions and non-electrolyte molecules through an interfacial boundary between the casting solution and the coagulating solution were investigated in the process of forming the cellulose membrane. For the cellulose membrane, with an increase in $Z, N(r)$ becomes narrower and the peak value of $N(r)$ increases on shifting the peak position to the smaller $r$ value side. For the CA membrane these dependences on $Z$ are reversed. Variation of $N(r)$ with $Z$ can be reasonably explained by change in the CA concentration in the casting solution with $Z$. For the cellulose membrane, water molecules in the casting solution are transported to the coagulation solution, resulting in an increase in the polymer concentration.
\end{abstract}

KEY WORDS Regenerated Cellulose Membrane / Cellulose Acetate Membrane / Micro-Phase Separation / Molecule Transport / Layer Structure / Pore Size Distribution / Membrane Potential / Phase Diagram /

The microfiltration (MF) membrane is widely said to be a symmetrical membrane, having an average pore diameter, as determined by the water flow rate method, larger than $50 \mathrm{~nm}$. However, the pore characteristics, revealed by the electron micrographic (EM) method, are not always the same between the two (front and back) surfaces of the membrane. Up to now several attempts ${ }^{1-3}$ were made, from EM observations on the cross section of MF membrane, to disclose the change in the internal pore structure. Unfortunately they remain at a very primitive

\footnotetext{
* To whom all correspondence should be addressed.
}

and qualitative state.

Except for very few membranes, such as Nucleopore ${ }^{\circledR}$ polycarbonate membrane, and Cellugard ${ }^{\circledR}$ polypropylene membrane, MF membranes are commercially available and in laboratory manufactured by the solvent cast process, in which the micro-phase separation occurs unavoidably. Recently, Kamide and Manabe $^{4}$ showed that the secondary particles formed in the separation govern principally the pore characteristics of the membrane and the radius of the secondary particles $S_{2}$ is dependent on the phase separation conditions, including the polymer concentration, and the two-phase volume ratio $R$. The theory pro- 
posed by them predicts that continuous variation in the phase separation conditions from the surface of the casting solution to the inside part brings about a systematic change in the value of $S_{2}$ and accordingly, a significant variation of the pore characteristics between the surface and the inside of the membrane. In fact, we occasionally experienced a case where the pore characteristics, obtained by EM method, of the front and back surfaces of the membrane are the same, but the average pore size $\bar{r}_{\mathrm{f}}$ determined by the flow method differs from that by the EM method. If one wishes to establish the relations between the pore characteristics and the performance of the membrane, the pore characteristics should not be limited to the surfaces, but be evaluated as a function of the distance $Z$ from the front surface. This motivated the present study.

In this article, an attempts were made to prepare a series of very thin (at most, $1 \mu \mathrm{m}$ ) sheets by slicing the MF membrane with a diamond knife in parallel to the surface and to evaluate the pore radius distribution $N(r)$ as a function of $Z$, by applying the EM method proposed so far ${ }^{5}$ and to show that the development of the layer structure is theoretically explained by comparing the observed $N(r)$ with the theoretical $N(r)$, calculated from experimental $S_{2}$ and $R$ values.

\section{EXPERIMENTAL}

\section{Porous Polymeric Membrane}

By evaporating the solvents of the solution of cellulose acetate (CA) with the total degree of substitution $《 F\rangle$ of 2.5 in $\mathrm{CaCl}_{2} \cdot 2 \mathrm{H}_{2} \mathrm{O}$ acetone-methanol-cyclohexanol system (15: $100: 25: 75$ in weight ratio) the CA membrane (sample code CA-1) with thickness of $150 \mu \mathrm{m}$ (for the dry membrane) was prepared through the micro-phase separation. The composition of the casting solution and pore characteristics were established in the preliminary experiments. ${ }^{6}$

The cellulose cuprammonium solution cast on a glass plate was immersed into a coagulation solution whose composition was ammonia-water-acetone of $0.56: 59: 40$ (in weight ratio). ${ }^{7}$ By changing the cellulose concentration of the casting solution such as 5,6 , 7.5 , and $10 \mathrm{wt} \%$, we obtained a series of membranes with different $N(r)$ (sample Code RC-1, $\mathrm{RC}-2, \mathrm{RC}-3$, and RC-4, respectively).

\section{Electron Microscopy}

The CA-1 and RC-2 membranes were embedded in blocks of epoxy resins (Epok 812 sold by Ouken Shouji, Japan) and acrylic resin (mixture of $n$-butyl acrylate and methyl methacrylate), respectively, and were sliced using an LKB 8800 ultrotome III (manufactured by LKB Co., Ltd., Sweden) parallel to the membrane surface to give ultra-thin sections of $0.1 \mu \mathrm{m}$ thickness for RC-2 membrane and of $1 \mu \mathrm{m}$ thickness for CA-1 membrane. These sections were prepared for each $20 \mu \mathrm{m}$ pitch of the distance $Z$ from the front surface as shown in Figure 1.

In the case of the RC membrane, the acrylic resin (mixture of $n$-buty acrylate and methyl the sections using chloroform. The sections were observed using a scanning electron microscope (JSM-U3 type SEM, manufactured by JEOL Co., Ltd., Japan). The sections of CA-1 membrane were observed without dissolution of the epoxy resin by using a transmission electron microscope (JEM-1200 EX type TEM, manufactured by JEOL Co., Ltd., Japan).

In order to observe the process of the phase separation (i.e., the casting process in industrial term) the solution cast was frozen instantaneously at $81 \mathrm{~K}$ in liq. $\mathrm{N}_{2}$ and fractured at $163 \mathrm{~K}$, and the fractured surface of the frozen solid, carbonized and metallized concurrently at $163 \mathrm{~K}$ under $10^{-7} \mathrm{mmHg}$, was observed under EM.

\section{Pore Radius Distribution}

A number of parallel test lines were drawn on the electron micrographs, whose magnifi- 


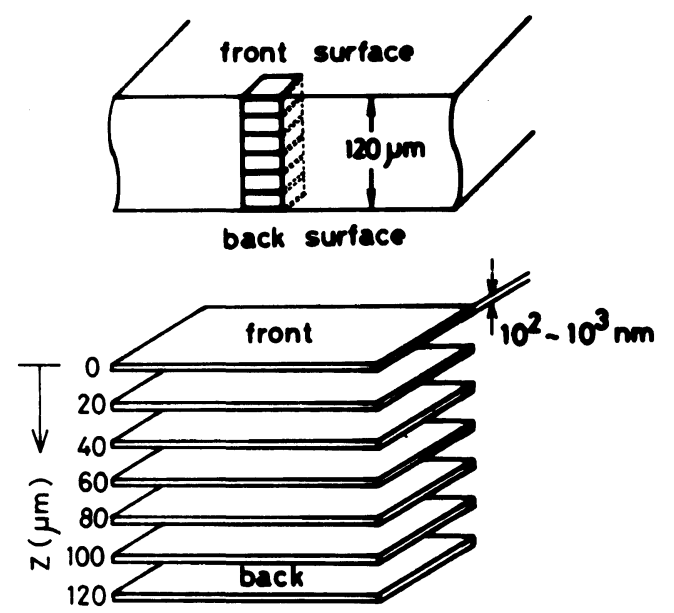

Figure 1. Schematic representation of the preparation of the seven ultra-thin sections with $10^{2}-10^{3} \mathrm{~nm}$ thickness at various $Z$ of $0,20,40,60,80$, and $120 \mu \mathrm{m}$ for $\mathrm{RC}$ membrane.

cation was ten thousand, of the ultra-thin sections of the membranes. The interval of the test lines was chosen as each test line penetrated more than ten pores. The length $y$, cutoff with pores, of the test line was measured and the distribution function of $y, F(y)$, was evaluated. Under the assumptions that the cylindrical pores dispersed randomly within a thin section and the dispersed state was homogeneous in this section, $F(y)$ was converted to the pore radius distribution $N(r)$ with the help of the stereology by the method proposed by Manabe et al. ${ }^{5}$ From $N(r)$, the $i$-th mean pore radius, for example, can be calculated.

$$
\bar{r}_{i}=\frac{\int_{0}^{\infty} r^{i} N(r) \mathrm{d} r}{\int_{0}^{\infty} r^{i-1} N(r) \mathrm{d} r} \quad(i=3 \text { and } 4)
$$

$\left(\bar{r}_{3} \cdot \bar{r}_{4}\right)^{1 / 2}$ is calculated from $\bar{r}_{3}$ and $\bar{r}_{4}$ obtained by eq 1 . Porosity $P_{\mathrm{r}}$ and pore density $N$ are also calculated from $N(r)$ as follows

$$
\begin{gathered}
P_{\mathrm{r}}=\pi \int_{0}^{\infty} r^{2} N(r) \mathrm{d} r \\
N=\int_{0}^{\infty} N(r) \mathrm{d} r
\end{gathered}
$$

\section{Cloud Point Curve (CPC)}

Six cellulose cuprammonium solutions with the concentration of cellulose (the viscosityaverage molecular weight $\bar{M}_{v}$ of $2.33 \times 10^{5}$ ) ranging from 1.0 to $9.09 \mathrm{wt} \%$ were prepared. Here, the weight ratio of the cellulose to copper and that of ammonia to water were kept constant at 2.53 and 0.089 , respectively. A given amount of acetone was added to the solutions, sealed in a glass tube under nitrogen atmosphere, followed by mechanical agitation for $5 \mathrm{~min}$ at $293 \mathrm{~K}$. Strictly speaking the total number of components of the solutions was five: cellulose, copper, ammonia, water, and acetone. But, remembering that the weight ratio of cellulose-to copper and that of ammonia to water of the casting solutions were, as described before, kept constant throughout the study, the solution was approximated as a quasi-ternary system, cellulose- $\mathrm{Cu}$, ammoniawater, and acetone.

Direct determination of CPC of these solutions was experimentally impossible due to the following reasons: (1) the solutions were not transparent, (2) the homogeneous mixing of acetone with the cuprammonium solution was not attainable instantly because of the high viscosity ( $\sim 50$ poise) of the solution. Then, we employed an indirect method for CPC determination. After the mechanical agitation, the solution was settled for $24 \mathrm{~h}$ and whether the detectable phase separation occurred or not was judged with the naked eye. The experiments were repeated two hundred or more times by changing the amount of acetone added to the solutions. In this way, the compositions of the solutions, which were homogeneous or phase-separated, were determined. The border line dividing the homogeneous and the phase-separated solutions thus determined on the triangle map was roughly regarded as CPC. The position of the border line was determined within an accuracy of $0.5 \mathrm{wt} \%$ in the acetone concentration. 
Table I. Composition of Polymer-lean (p.l.) phase and polymer-rich (p.r.) phase separated at $298 \mathrm{~K}$ from preparation original solution

\begin{tabular}{|c|c|c|c|c|c|c|c|}
\hline \multirow{2}{*}{$\begin{array}{c}\text { Code } \\
\text { number }\end{array}$} & \multirow{2}{*}{ Phase } & \multirow{2}{*}{$\begin{array}{c}\text { Phase } \\
\text { ratio }\end{array}$} & \multicolumn{5}{|c|}{ Composition $/ w t \%$} \\
\hline & & & Cellulose & Acetone & $\mathrm{NH}_{3}$ & $\mathrm{Cu}$ & $\mathrm{H}_{2} \mathrm{O}$ \\
\hline \multirow[t]{3}{*}{1} & Preparative original solution & \multirow{3}{*}{$\begin{array}{c}- \\
9.38\end{array}$} & 2.3 & 23.2 & 5.9 & 0.9 & 67.1 \\
\hline & p.l. & & 0.8 & 20.0 & 5.4 & 0.7 & 73.1 \\
\hline & p.r. & & 12.8 & 44.5 & 9.2 & 4.5 & 26.8 \\
\hline \multirow[t]{3}{*}{2} & Preparative original solution & \multirow{3}{*}{-} & 4.7 & 20.9 & 5.8 & 1.9 & 65.5 \\
\hline & p.l. & & $0 \sim$ & 15.9 & 4.1 & 0.7 & 79.3 \\
\hline & p.r. & & 7.9 & 24.2 & 6.8 & 2.6 & 56.9 \\
\hline \multirow[t]{3}{*}{3} & Preparative original solution & \multirow{3}{*}{$\begin{array}{c}- \\
0.26\end{array}$} & 6.5 & 18.5 & 5.7 & 2.6 & 65.0 \\
\hline & p.l. & & $0 \sim$ & 14.7 & 4.0 & 0.9 & 80.3 \\
\hline & p.r. & & 8.4 & 18.8 & 6.1 & 3.0 & 62.5 \\
\hline
\end{tabular}

\section{Compositions of Two Phases Coexisting at Equilibrium}

Three solutions with cellulose concentrations of $2.3,4.7$, and $6.5 \mathrm{wt} \%$, whose compositions are given in Table I, were allowed to stand for $48 \mathrm{~h}$ at $293 \mathrm{~K}$ after agitation. The concentration of acetone in these solutions was about $1 \mathrm{wt} \%$ higher than that of CPC. The thermodynamic equilibrium was considered to be attained when $R$ became time-independent. The compositions of the co-existing two phases after phase separation were determined by the following methods:

(a) Polymer-Lean Phase. The concentrations of acetone, ammonia and water of the polymer-lean phase were determined by the gas chromatographic method using a Shimadzu gas chromatograph model GC-3BT, combined with the column gel of Porapak ${ }^{\circledR} \mathrm{Q}$ manufactured by Waters Associate Inc., U.S.A. The column temperature was $413 \mathrm{~K}$, and the carrier gas was $\mathrm{N}_{2}$. The copper concentration of the phase was determined by the chelate analysis technique. The polymer-lean phase, separated from the polymer-rich phase, was added with a mixture of $1 \mathrm{~N}$ ammonia and $1 \mathrm{~N} \mathrm{NH}_{4} \mathrm{Cl}$ aq solution acting as a buffer solution with $\mathrm{pH}=8$ and then titrated at $293 \mathrm{~K}$ with $0.01 \mathrm{M}$ EDTA aq solution (manufactured by Kishida Chemical Co., Japan) using Murexide powder (manufactured by Kishida Chemical Co., Japan) as an indicator. In this experiment, to keep $\mathrm{pH}$ at 8 was very important in order to avoid co-precipitation of trace amounts of co-existing metals such as $\mathrm{Na}^{+}$, $\mathrm{K}^{+}$, and $\mathrm{Ca}^{2+}$. The cellulose concentration of the polymer-lean phase was too low to determine directly and was indirectly evaluated from the experimental $R$, the density of the phase and the cellulose concentration of the polymer-rich phase.

(b) Polymer-Rich Phase. The concentrations of acetone and copper in the phase were determined in the same manner as used for the polymer-lean phase. The cellulose concentration $V_{\mathrm{p}}$ was gravimetrically evaluated from the precipitate formed by adding a sufficient amount of $2 \mathrm{wt} \%$ aq sulfuric acid to the phase. The concentration of ammonia and water were calculated indirectly from those of the polymer-lean phase and the casting solution.

Transport of Ions and Molecules through the Interfacial Boundary Layer between the Casting Solution and Coagulating Solution in the Set Process

Figure 2 demonstrates the apparatus con- 


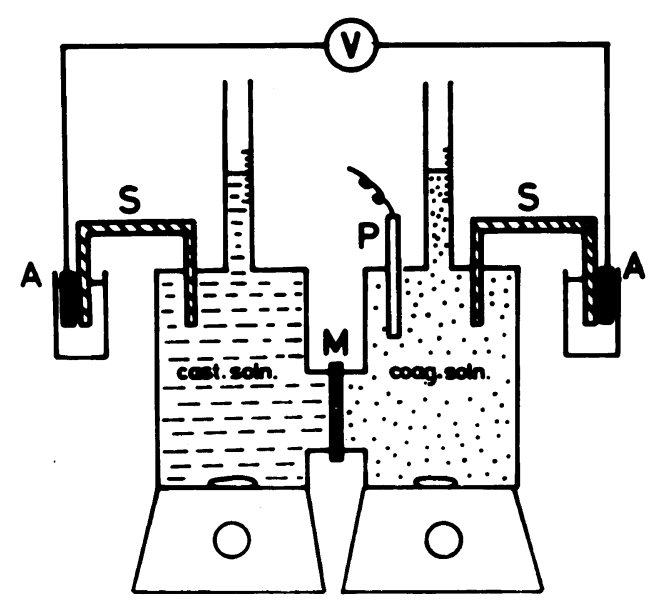

Figure 2. Apparatus for determination of the transport of ions and molecules through boundary layer between the casting solution and coagulating solution:

$\mathrm{A}, \mathrm{Ag} / \mathrm{AgCl}$ electrode; $\mathrm{M}$, membrane; $\mathrm{P}, \mathrm{pH}$ electrode; $\mathrm{S}$, salt bridge; $\mathrm{V}$, volt meter.

structed for determining the transport of ions and molecules. The casting solution was first poured into the cell and then the coagulating solution was filled in the alternative cell. In order to make quickly a stable interfacial plane after the contact of the casting solution with the coagulation solution, the porous polytetrafluoroethylene membrane (Mitex Filter LCWP ${ }^{\circledR}$, manufactured by Millipore Corp., U.S.A.) with nominal mean pore size as indicated of $10 \mu \mathrm{m}$ was placed between the casting solution cell and the coagulation solution cell. The interfacial potential between the coagulating solution and the casting solution Em, originating by the ion transportation immediately after the contact of the casting solution with the coagulating solution was measured by using the $\mathrm{Ag}-\mathrm{AgCl}$ electrode- $\mathrm{KCl}$ salt bridge system. Em was detected as the difference of electric potential of the casting solution from that of the coagulating solution. Here, the former was a cellulose-copperammonia-water mixture with the composition of $6.0: 2.38: 7.2: 81.8$ (in weight ratio) and the latter was a system consisting of ammoniawater-acetone with the composition of
0.56:59:40 (in weight ratio). The $\mathrm{OH}^{-}$(or $\mathrm{H}^{+}$) ion concentration in the coagulating solution was estimated by a $\mathrm{pH}$ meter, manufactured by Horiba Ltd., Japan and $\mathrm{Cu}^{2+}$ concentration in the coagulation solution was determined colorimetrically by a Shimadzu recording spectrophotometer UV-300. The volumetrical change due to the transportation of mainly water and acetone from one cell to another was evaluated from the movement of the meniscus in a capillary attached to the upper part of the casting solution cell (see, Figure 2). The minor contribution of the transportation of $\mathrm{NH}_{4} \mathrm{OH}$ to the total volumetric change was neglected because only a very small amount of $\mathrm{NH}_{4} \mathrm{OH}$ contaminated the coagulation solution. The experiments were carried out at $298 \mathrm{~K}$.

\section{RESULTS AND DISCUSSION}

Figure 3 shows the electron micrographs of the ultra-thin sections of RC-2 membrane at various $Z$. The white network structure in the photograph at $Z=0 \mu \mathrm{m}$ evidently consists of small spherical particles having a radius $\left(S_{2}\right)$ of about $0.2 \mu \mathrm{m}$ and the black portion corresponds to pores. The particles are obviously secondary particles, as defined by Kamide and Manabe in the previous work, ${ }^{4}$ grown up from the primary particles of the polymer-rich phase separated from the casting solution. A detailed observation of the network structure of the thin section at $Z \neq 0 \mu \mathrm{m}$ showed the existence of the particles although the spherical characteristics became obscure due to slicing of the particles.

We observed directly the formation of the super structure from the casting solution using a frozen fracture method. The electron micrographs of the fracture showed that the phase separation proceeded from the front surface to the back surface in the regenerated cellulose membrane. ${ }^{8}$

Figure 4 shows $N(r)$, evaluated by analyzing the EM photographs in Figure 3, for the RC 


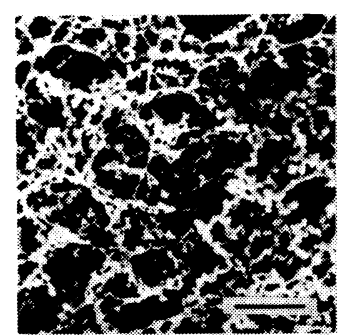

$Z=0 \mu \mathrm{m}$

$Z=0 \mu \mathrm{m}$
font surface

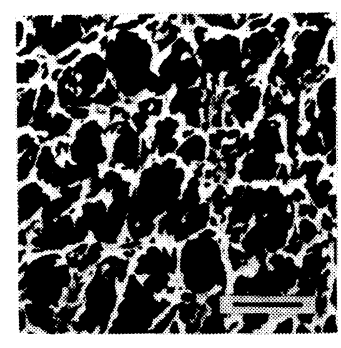

$Z=20 \mu \mathrm{m}$

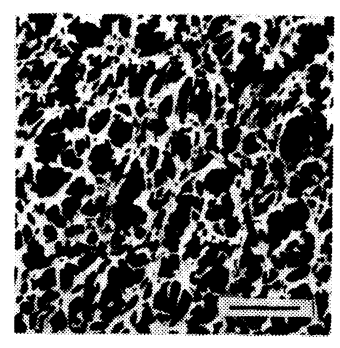

$Z=40 \mu \mathrm{m}$

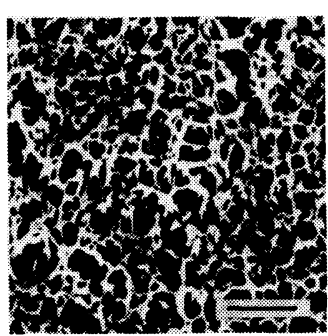

$Z=60 \mu \mathrm{m}$

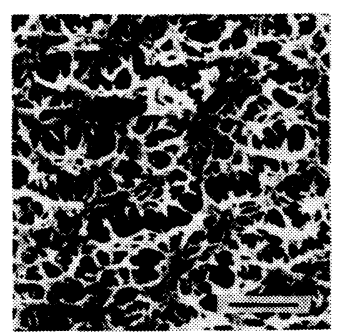

$Z=80 \mu \mathrm{m}$

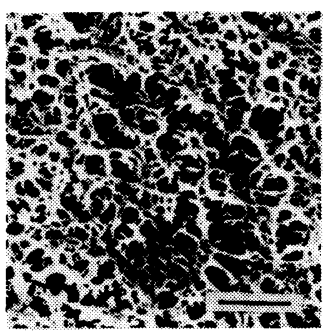

$Z=100 \mu \mathrm{m}$

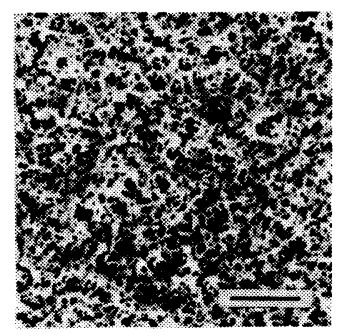

$Z=120 \mu \mathrm{m}$

back surface

Figure 3. Electron micrographs of the ultra-thin sections at various $Z$ for RC-2 membrane: scale bars stand for $5 \mu \mathrm{m}$.

membrane at various $Z$. Here, $N(r)$ was evaluated assuming that the ultra-thin sections of the membrane have the straight-through cylindrical pore. With an increase in $Z, N(r)$ becomes narrower and the peak value of $N(r)$ increases and the peak position of $N(r)$ shifts to smaller $r$ value. If the inner layer with the same $Z$ are compared, all the $N(r) v s$. $r$ curves coincide fairly well (Figure $4 b$ ). In other words, interestingly, the supermolecular structures, detected by EM, of the thin sections at the same $Z$ are almost the same. This fact is acceptable by considering that the inner layer at the same $Z$ is formed at the same instant under the same phase separation conditions such as temperature and composition.

\section{Mechanisms of the Development of the Layer Structure}

According to Kamide and Manabe, ${ }^{4,6}$ pores in a porous polymeric membrane are formed through the micro-phase separation of polymer solution. If the initial polymer concen- tration is smaller than the critical solution concentration, the polymer-rich phase separates as small particles (primary particles) between 10 and $30 \mathrm{~nm}$ in diameter. The primary particles amalgamate into larger secondary particles with diameters of 50 to $300 \mathrm{~nm}$. The secondary particles subsequently coagulate to form pores. The theoretical equation to give pore radius distribution function $N(r)$ in an imaginary plane of a membrane was derived under the following assumptions: (1) the polymer-rich phase generated through the micro-phase separation makes the secondary particle having a radius of $S_{2}$, (2) the polymerlean phase generated exists as the collective of the vacant particles having a radius of $S_{2}$, (3) the total number of the secondary and vacant particles is given by $1 /\left[(4 \pi / 3) \cdot S_{2}{ }^{3}\right]$, (4) the packing state of the secondary and vacant particles is random and the hexagonal closest packing is completed with six, nearest neighbor particles, (5) a pore is defined as the space constructed by vacant particles connected to 

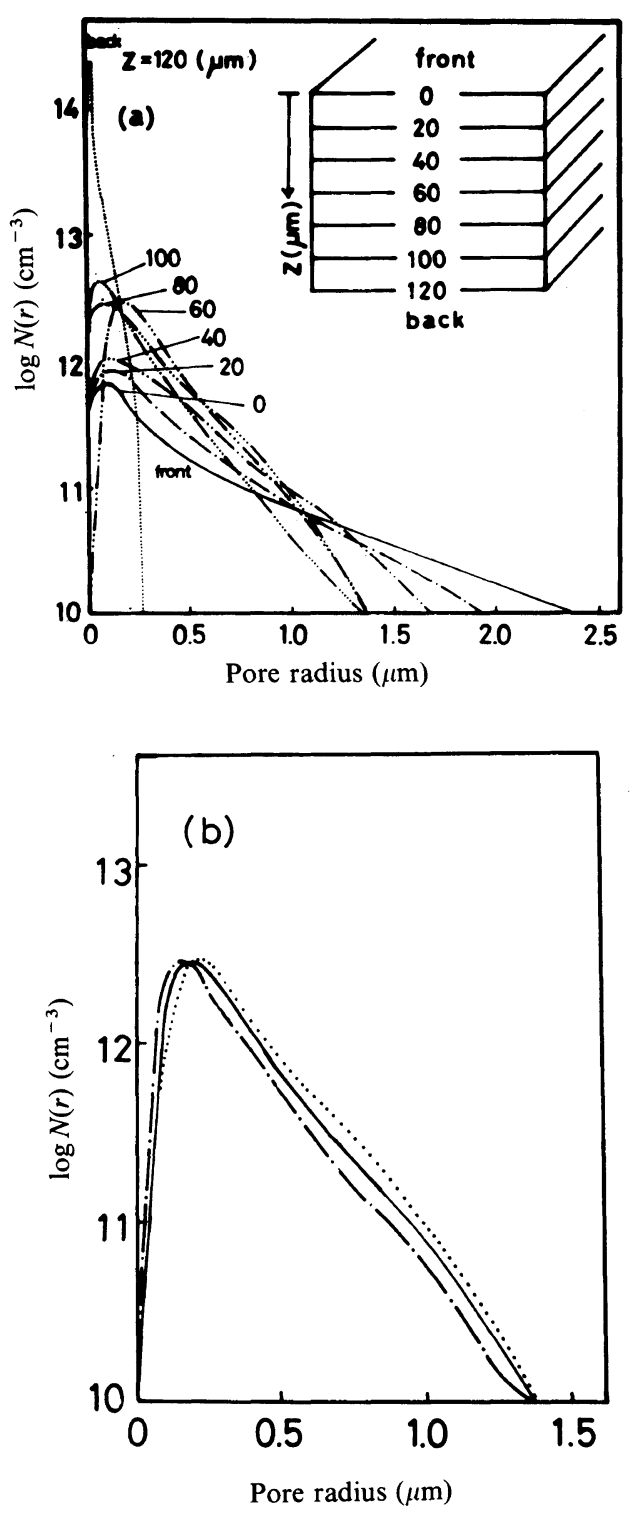

Figure 4. $N(r)$ of the ultra-thin section for RC-2 membrane at various $Z$ evaluated from the electron micrographs shown in Figure 3: (a), $N(r)$ vs. $r$ curves of the sections with different $Z$; (b), $N(r)$ vs. $r$ curves of the section with $Z=60 \mu \mathrm{m}$ at different location.

each other and surrounded perfectly by secondary particles within an imaginary plane in the membrane, (6) the pore shape is approximated to be circular and (7) the radius of the pore of the dry membrane $r$ changes from that of the wet membrane $r_{\mathrm{w}}$ and is calculated by the polymer concentration of the polymer-rich phase $V_{\mathrm{p}}$ and the densities of the polymer-rich phase and the polymer itself, $\rho_{\mathrm{s}}$ and $\rho_{\mathrm{p}}$, respectively using the following equation of

$$
r=r_{\mathrm{w}}+\left[1-V_{\mathrm{p}}\left(\rho_{\mathrm{s}} / \rho_{\mathrm{p}}\right)^{1 / 3}\right] S_{2} .
$$

The equation thus derived is given by

$$
\begin{aligned}
\log N(r)= & \log 2 N /\left\{\left(S_{2}{ }^{2}(1+\bar{x})\right\}\right. \\
+ & \log \left[r-\left\{1-\left(V_{\mathrm{p}} \rho_{\mathrm{s}} / \rho_{\mathrm{p}}\right)^{1 / 3}\right\} S^{2}\right] \\
+ & {\left[r / S_{2}-1+\left(V_{\mathrm{p}} \rho_{\mathrm{s}} / \rho_{\mathrm{p}}\right)^{1 / 3}\right]^{2} } \\
& \times \log [\bar{x} /(1+\bar{x})]
\end{aligned}
$$

with

$$
\bar{x}=[R /(1+R)]\left(1 / \pi S_{2}^{2} N\right)
$$

$N$ can be calculated numerically from $S_{2}$ and $R$ so as to satisfy the boundary conditions that a pore should be surrounded by secondary particles.

According to our theory, ${ }^{4} N(r)$ and also mean pore radii depend mainly on $S_{2}$ and $R$. With an increase in $R$ or $S_{2}$, mean pore radii and porosity increase. Theoretical and experimental studies on phase separation show that $R$ increases with the decrease in $V_{\mathrm{p}}$. Accordingly the porosity and the mean pore radius increase with the decrease in $V_{\mathrm{p}}$ as predicted by our theory and experiment. ${ }^{4}$ Therefore, it is theoretically expected that the membrane with larger mean pore radius can be prepared from a solution of lower polymer concentration.

For RC-2 membrane, whose inner morphology was shown in Figure 3, the following quantities were experimentally determined: $S_{2}=0.177 \mu \mathrm{m}$ (at $Z=120 \mu \mathrm{m}$, in other words, the back surface), $R=2.0, V_{\mathrm{p}}=0.085, \rho_{\mathrm{s}}=1.09$ $\mathrm{g} \mathrm{cm}^{-3}, \rho_{\mathrm{p}}=1.50 \mathrm{~g} \mathrm{~cm}^{-3}$. From $S_{2}$ and $R$ data, $N$ was calculated numerically to be $1.75 \times 10^{8}$ number $/ \mathrm{cm}^{2}$. Using these quantities $N(r)$ for the back surface of RC-1 membrane was calculated from eq 2 and 3 and is shown in Figure 5. The figure contains also $N(r)$ of the back 


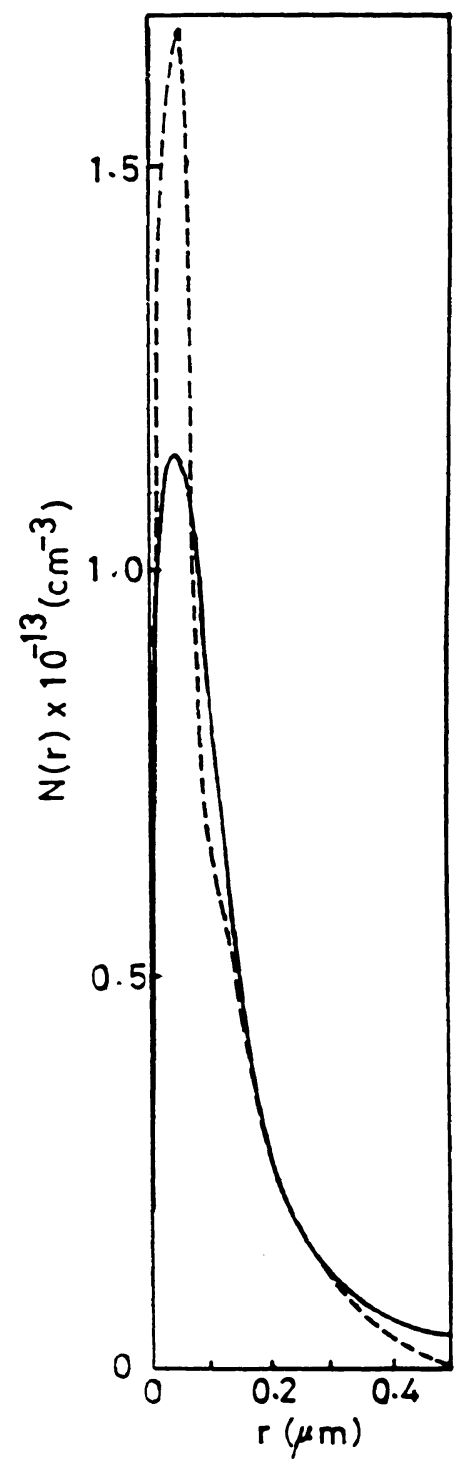

Figure 5. Comparison between theoretical $N(r)$ and experimental $N(r)$ for RC-1 membrane: Full line, experimental $N(r)$ of the section at $Z=120 \mu \mathrm{m}$ estimated by electron microscopic method of the basis of cylindrical pore model; broken line, theoretical $N(r)$ calculated using eq 2 and 3 and the experimental value of $S_{2}=$ $0.177 \mu \mathrm{m}, R=2.0, V_{\mathrm{p}}=0.085, \rho_{\mathrm{s}}=1.09 \mathrm{~g} \mathrm{~cm}^{-3}, \rho_{\mathrm{p}}=$ $1.5 \mathrm{~g} \mathrm{~cm}^{-3}$.

surface of the membrane, directly estimated by the EM method. The two $N(r)$ vs. $r$ curves, directly and theoretically estimated, agree well,

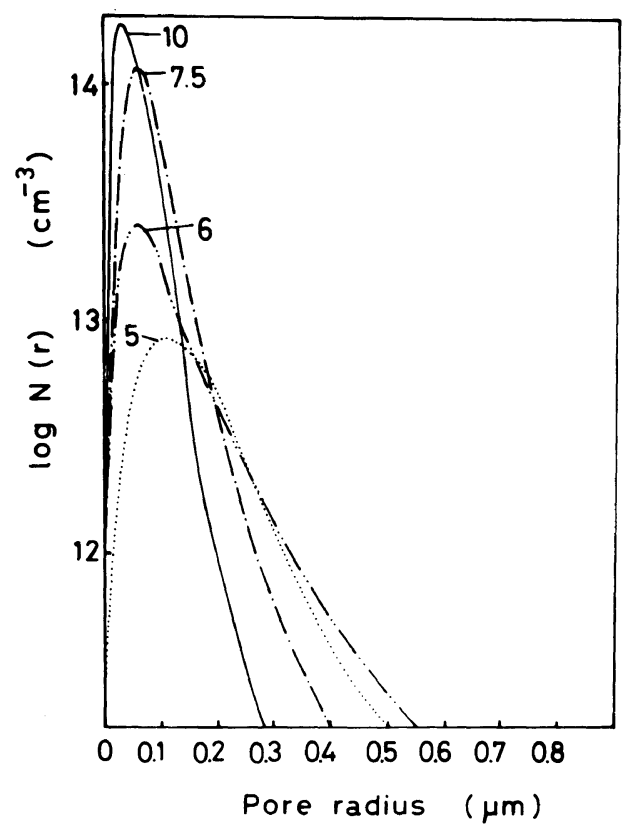

Fig. 6. Effect of $V_{\mathrm{p}}$ of the as-prepared casting solution on $N(r)$ at $Z=120 \mu \mathrm{m}$ (back surface) for RC membrane. The figure indicates $V_{\mathrm{p}}$ values.

indicating that the pore characteristics of $\mathrm{RC}$ membrane can be reasonably interpreted by the theory proposed by Kamide and Manabe. ${ }^{4}$

Then, a systematic change in $N(r)$ with $Z$, as observed in Figure 4 can also be explained in terms of our theory ${ }^{4}: R$ and/or $S_{2}$ may increase with an increase in $Z$ for RC-1 membrane. Considering that the variation of $S_{2}$ with $Z$ is very slight in actual experiments (see, Figure 3), we can conclude that $R$ must decrease significantly with increasing $Z$. In another experiments (see, Table I), we observed occasionally for cellulose cuprammonium solution-acetone system that $R$ decreases with an increase in the cellulose concentration in the casting solution and the latter is a main factor governing $R$. Therefore, we can predict that the cellulose concentration of the part of the solution, corresponding to a thin layer section at a distance $Z$ from the front surface of dry membrane, increases with $Z$, at least for RC-2 membrane. The validity of this prediction can 


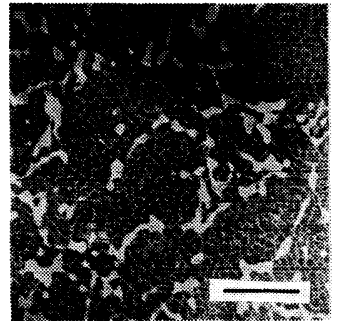

$Z=25 \mu \mathrm{m}$

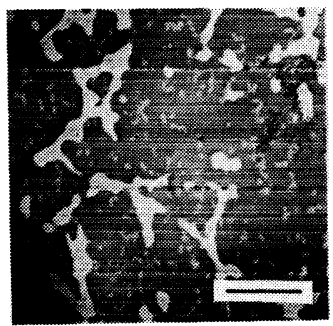

$Z=100 \mu \mathrm{m}$

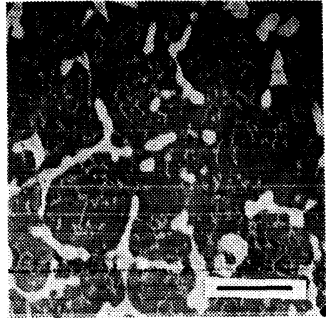

$Z=50 \mu \mathrm{m}$

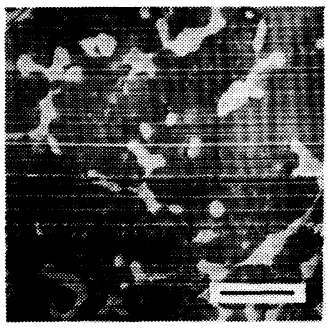

$Z=125 \mu \mathrm{m}$

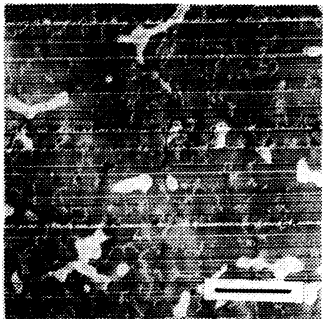

$Z=75 \mu \mathrm{m}$

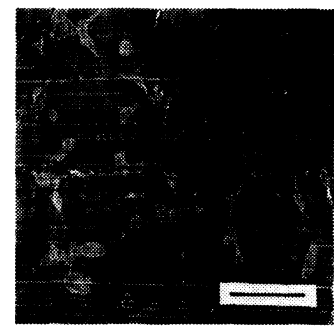

$Z=150 \mu \mathrm{m}$ back surface

Figure 7. Electron micrographs of ultra-thin sections at various $Z$ for CA-1 membrane: scale bars stand for $5 \mu \mathrm{m}$.

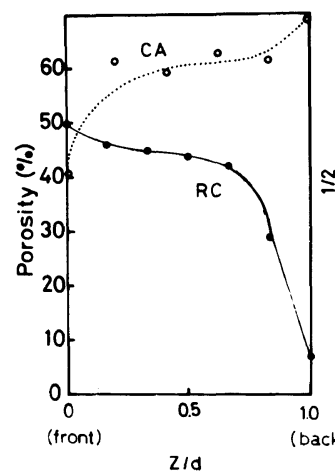

(a)

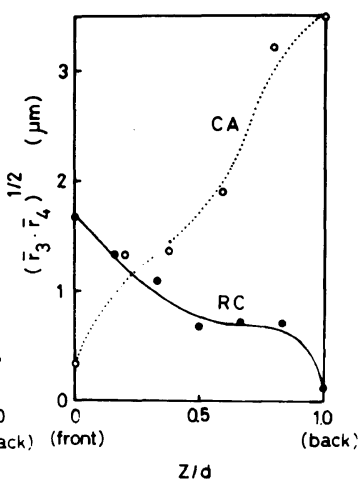

(b)
Figure 8. Changes in pore characteristics with $Z / d$ for $\mathrm{CA}$ and RC membranes: $d$ is the thickness of the membrane; $\mathrm{O}, \mathrm{CA}$ membrane; $\mathrm{RC}$ membrane.

be judged experimentally from the dependence of $N(r)$ on the cellulose concentration, as shown in Figure 6 in which $N(r)$ of the back surface of RC-1 RC-4 membranes is shown as a function of the cellulose concentration. The effect of the cellulose concentration on $N(r)$ curve for a given $Z$ is qualitatively similar to that of $Z$ at constant concentration.

Figure 7 shows the transmission electron micrographs of the ultra-thin sections at various distance $Z$ from the front surface for CA1 membrane. The black part is the pore. The various pore characteristics such as $N(r), \bar{r}_{i}$ $(i=3,4)$, the porosity $P_{\mathrm{r}}$ and the pore shape were estimated from Figure 7.

Figure 8 shows the plot of $P_{\mathrm{r}}$ and $\left(\bar{r}_{3} \cdot \bar{r}_{4}\right)^{1 / 2}$ vs. $Z / d$ ( $d$, the thickness of the membrane) of CA-1 and RC-1 membranes. In the CA-1 membrane both $P_{\mathrm{r}}$ and $\left(\bar{r}_{3} \cdot \bar{r}_{4}\right)^{1 / 2}$ increase with $Z$, but in the RC-1 membrane, the $Z$ dependence is just the reverse. The discussion made for RC-1 membrane can also be applied to the CA membrane; i.e., the polymer concentration $V_{\mathrm{p}}$ for the layer at $Z$ may decrease with increasing $Z$.

\section{Change in the Polymer Concentration with $Z$ in} the Casting Process

Figure 9 shows CPC (full line) at $293 \mathrm{~K}$ for cellulose, copper, ammonia, water, and acetone 

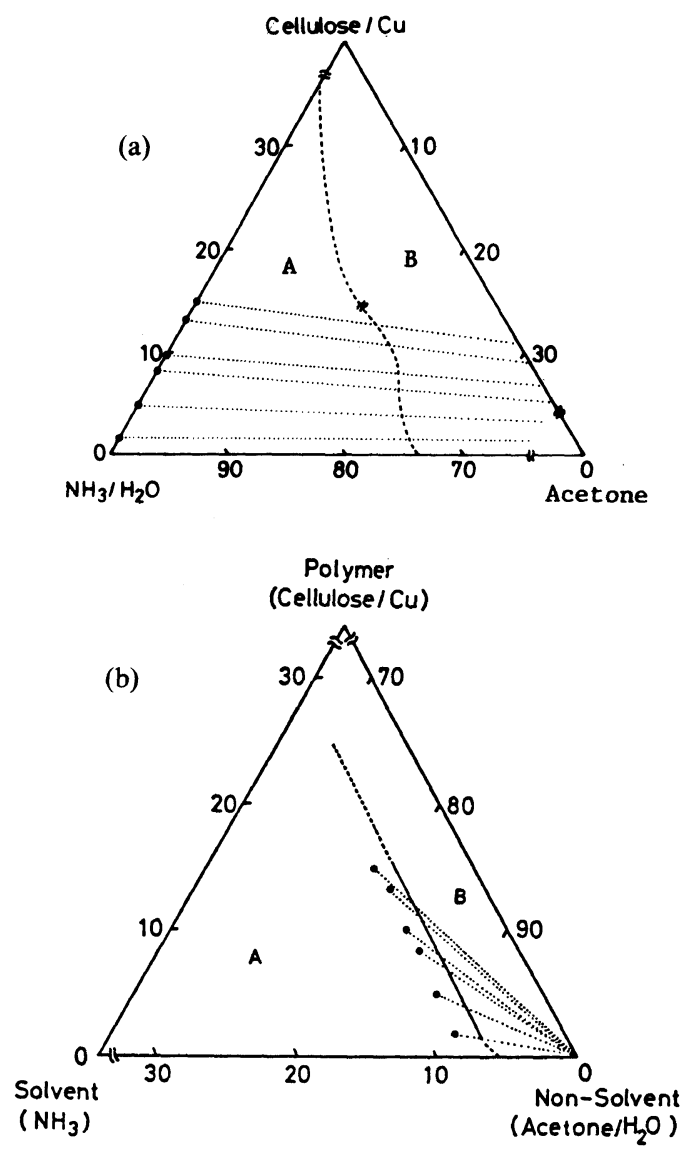

Figure 9. Cloud point curve of the casting solution for RC membrane at $293 \mathrm{~K}$ : (a), quasi-ternary system of (cellulose $/ \mathrm{Cu}, 2.53$ in wt. ratio), $\left(\mathrm{NH}_{3} / \mathrm{H}_{2} \mathrm{O}, 0.089\right.$ in wt. ratio), and acetone; (b), quasi-ternary system of (cellulose $/ \mathrm{Cu}$ ), (acetone $/ \mathrm{H}_{2} \mathrm{O}$ ), and $\mathrm{NH}_{3} ; \mathrm{A}$ and $\mathrm{B}$ indicate the single phase region and two-phase separated region, respectively; $\bigcirc$, starting point.

system. In order to represent the process of the formation of pore, the quasi-ternary system of (cellulose $/ \mathrm{Cu}$ )-(ammonia/ $\mathrm{H}_{2} \mathrm{O}$ )-acetone was employed in Figure 9a. That is, the composition of the casting solution changes along the dotted line from the starting points shown by closed circles. In the $\mathrm{A}$ region, the system remains a single homogeneous phase and in the $\mathrm{B}$ region, two-phase separation occurs. As is shown in Figure 9b, CPC can be accurately represented by a straight line with a constant ammonia concentration (i.e., $6 \mathrm{wt} \%$ ) when the quasi-ternary system of (cellulose/Cu) $-\mathrm{NH}_{3}-$ (acetone $/ \mathrm{H}_{2} \mathrm{O}$ ) is employed. Figure $9 \mathrm{~b}$ shows that the occurrence of the phase separation is mainly dominated by the ammonia concentration and is only slightly influenced by the acetone concentration, at least if the.cellulose concentration lies in the range $0.5-11 \mathrm{wt} \%$. The compositions of coexisting two phases, separated from the initial solution, are summarized in Table I. It must be noted that the binodal curve cannot be simply shown in a triangle ordinate, because of the significant difference in the weight ratios of cellulose $/ \mathrm{Cu}$, $\mathrm{NH}_{3} / \mathrm{H}_{2} \mathrm{O}$, and acetone $/ \mathrm{H}_{2} \mathrm{O}$ between the two phases. In other words, no solvent mixture can be treated as a "single solvent".

Inspection of Table I leads us to the conclusion that when the two phase separation occurs for the cellulose-copper-ammoniawater-acetone system, copper, ammonia, and acetone are also concentrated in the polymerrich phase, while water molecules remain in the polymer-lean phase.

As soon as the casting solution contacts the coagulation solution, the components are transported by diffusion due to the concentration gradient and in part by the electropotential gradient, through the interfacial plane to the coagulation cell. Figure 10 shows the time-dependence of the interfacial potential between the coagulating solution and casting solution $\mathrm{Em}, \mathrm{pH}$ of the coagulation solution and the volumetrical change of the casting solution. Here, the casting solution with the composition of cellulose-copperammonia-water-acetone $=6.0: 2.38: 7.2$ : 81.8:0 (in weight ratio) contacted with coagulating solution with a similar ratio, $0: 0$ : $0.56: 59: 40$ at $298 \mathrm{~K}$. The densities of these solutions were approximately 1.0 and 0.91 , respectively.

Figure 10a shows that Em initially increases very rapidly (this is stage Ia) and after passing the maximum within $0.1 \mathrm{~s}$, decreases quickly approaching a minimum. This range is noted as stage Ib. The potential increases again 


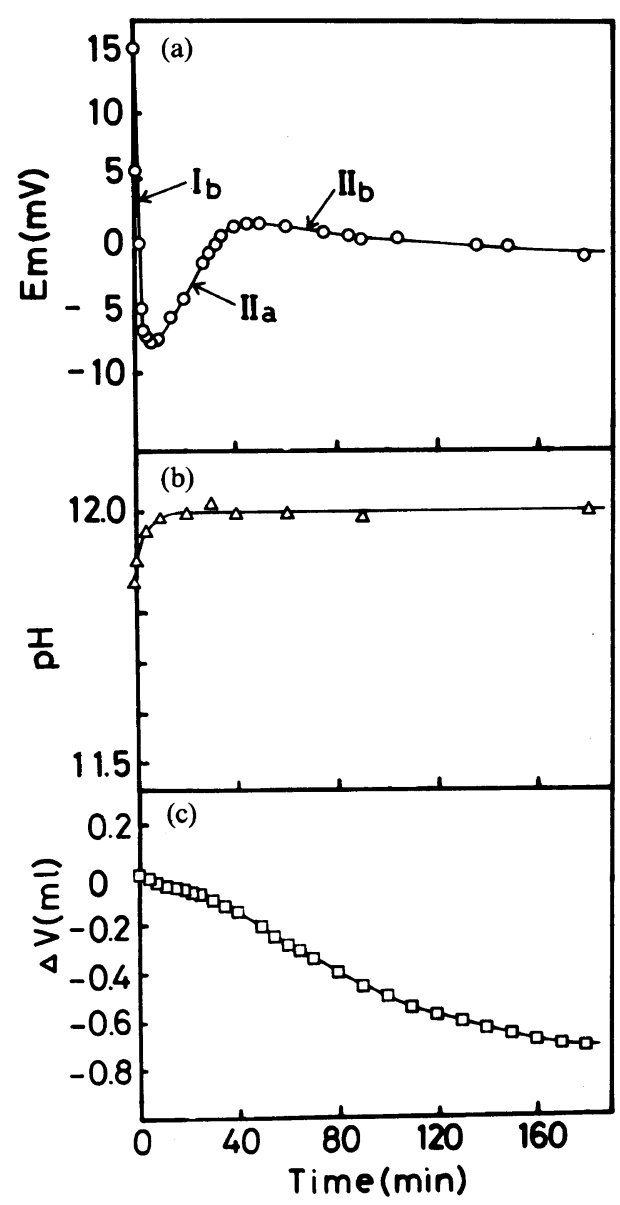

Figure 10. Changes in the interfacial potential Em (a), $\mathrm{pH}$ value of the coagulating solution (b) and volume change of the casting solution (c) with time after contact of the solutions with each other.

gradually to attain a small maximum and decreases again. This range is stage II. In short, the Em-time curve reveals two peaks, divided by a minimum. On both stages Ia and IIa, Em increases with time, suggesting that the ion with negative charge (in this case, $\mathrm{OH}^{-}$) moves from the casting solution to the coagulation solution and/or the ion with positive charge (in this case, copper ion $\left(\mathrm{Cu}^{2+}\right)$ and/or $\mathrm{NH}_{4}{ }^{+}$) moves to the opposite direction. In regions $\mathrm{Ib}$ and $\mathrm{IIb}$, the direction of the movement is the reverse of that in regions Ia and IIa.
Figure $10 \mathrm{~b}$ indicates that $\mathrm{OH}^{-}$ion is transported from the casting solution to the coagulation solution over the whole range of investigation. The coagulation bath became blue in stage IIb.

The results by dilatometry in Figure 10c show the occurrence of significant volumetrical flow from the casting solution to the coagulation solution over the whole range. It is clear from Table I that cellulose molecules, $\mathrm{Cu}^{2+}$, ammonia $\left(\mathrm{NH}_{4}{ }^{+}\right.$or $\left.\mathrm{NH}_{4} \mathrm{OH}\right)$, and water molecules in the casting solution are transported to the coagulation solution and acetone molecules move in the opposite direction.

From the above experimental results, we can summarize the transportation of nonelectrolyte and ions as:

Stage Ia, transportation of $\mathrm{OH}^{-}$ion to the coagulation solution is the most dominant.

Stage $\mathrm{Ib}$, the $\mathrm{OH}^{-}$ion flux becomes smaller because of the plus charge of the casting solution and $\mathrm{NH}_{4}^{+}$ion is accelerated to diffuse from the casting solution to the coagulation solution by the plus charge of the casting solution.

Stage IIa, the $\mathrm{NH}_{4}{ }^{+}$ion flux from the casting solution to the coagulation solution decreases continuously and the flux of some unknown positive ion (acetone or acetone complex with $\mathrm{NH}_{4}{ }^{+}$) from the coagulation solution to the casting solution is dominant.

Stage IIb, the diffusion of $\mathrm{Cu}^{2+}$ ion to the coagulation solution becomes pronounced.

The water flux in weight-time unit from the casting solution is always larger than that of acetone from the coagulation solution judging from the increase in volume of the coagulation solution.

The magnitude of mole flux of non-electrolyte component $i, f_{i}\left(\mathrm{~mol} \mathrm{~cm} \mathrm{~cm}^{-2} \mathrm{~s}^{-1}\right)$ can be 


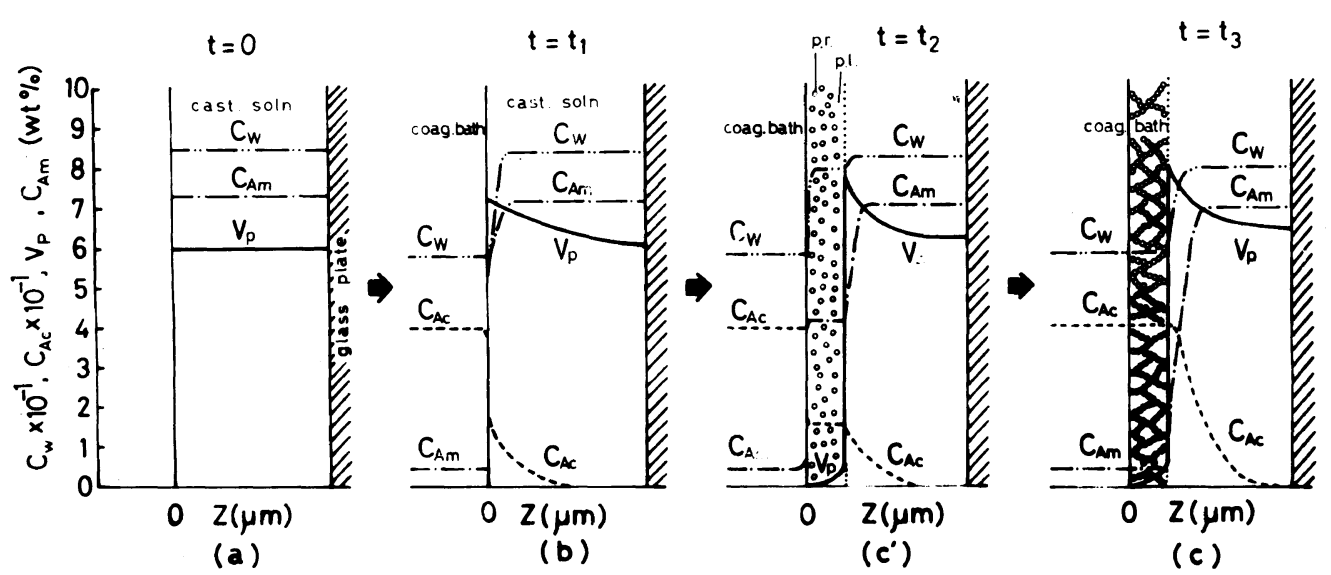

Figure 11. Changes in the profile of the composition of the solution for RC membrane formation as a function of $Z$ with time $t$ after casting: (a), immediately after casting on the glass plate ( $t=0$ ); (b), at an arbitrary time $\left(t=t_{1}\right)$ before the phase separation; $\left(\mathrm{c}^{\prime}\right)$, immediately after the occurrence of the phase separation near the boundary of the casting solution $\left(t=t_{2}\right) ;(\mathrm{c})$, after mixing of the polymer-lean phase and casting solution $\left(t=t_{3}\right)$.

estimated from the relation

$$
f_{i}=-D_{i} \partial C_{i} / \partial Z
$$

where $D_{i}$ is the diffusion coefficient of the component $i, \partial C_{i} / \partial Z\left(\mathrm{~mol} \mathrm{~cm}^{-4}\right)$, the concentration gradient of the component $i$ at the interfacial boundary layer. $D_{i}\left(\mathrm{~cm}^{2} \mathrm{~s}^{-1}\right)$ was found to be $1.77 \times 10^{-9}(288 \mathrm{~K})^{9}$ for ammonia (in water), $1.16 \times 10^{-9}$ (at $\left.293 \mathrm{~K}\right)^{10}$ for acetone (in water) and $2.27 \times 10^{-9}(293 \mathrm{~K})^{10}$ for water and the relative ratios of $\partial C_{i} / \partial Z\left(\mathrm{~mol} \mathrm{~cm}^{-4}\right)$ of ammonia and acetone to water were estimated from the compositions of the casting solution and the coagulating solution to be 0.240 and -0.379 , respectively. Therefore, the relative magnitudes of $f_{i}$ of ammonia, acetone and water were roughly calculated using eq 6 to be $-0.187,0.194$, and -1.00 (in mol ratio). The total flux (in mol) of water and ammonia ( $f=$ $\left.\sum_{i} f_{i}=-0.187-1.00=-1.187\right)$ from the cast-

ing solution to the coagulation solution is larger than $f_{i}$ of acetone $(0.194)$. This is consistent with the experimental results on the total volumetric change of the casting solution.

Now, we can draw a profile of the compositions of the casting and phase-separation solutions for various times elapsed after the contact (Figure 11).

Figure $11 \mathrm{a}$ is a schematic representation of the change in the composition as the function of the distance from the interfacial surface of the casting solution immediately after casting. In Figure 11b, the concentration of cellulose $\left(V_{\mathrm{p}}\right)$ near $Z=0$ of the casting solution $V_{\mathrm{p}}$ $(Z=0)$ becomes more than $6 \mathrm{wt} \%$ (i.e., $V_{\mathrm{p}}$ of the original solution) due to the transportation of water from the casting solution to the coagulation solution. The concentration of water $\left(C_{\mathrm{W}}\right)$, ammonia $\left(C_{\mathrm{Am}}\right)$, and acetone $\left(C_{\mathrm{Ac}}\right)$ near $Z=0$ of the casting solution change due to differences in their diffusional transportation velocity. When $C_{\mathrm{Am}}(Z=0)$ is below $c a$. $6 \mathrm{wt} \%$, two-phase separation occurs (see, Figure 9b). The polymer-lean phase builds up a new boundary to the casting solution tentatively as shown in Figure $11 c^{\prime}$. The polymerrich phase appears first as primary particles, which grow to secondary particles during the process of the phase separation and a network structure is formed by collision of the particles (the composition of the polymer-rich phase is omitted from Figure 11). The component molecules in the polymer-lean phase mix in- 

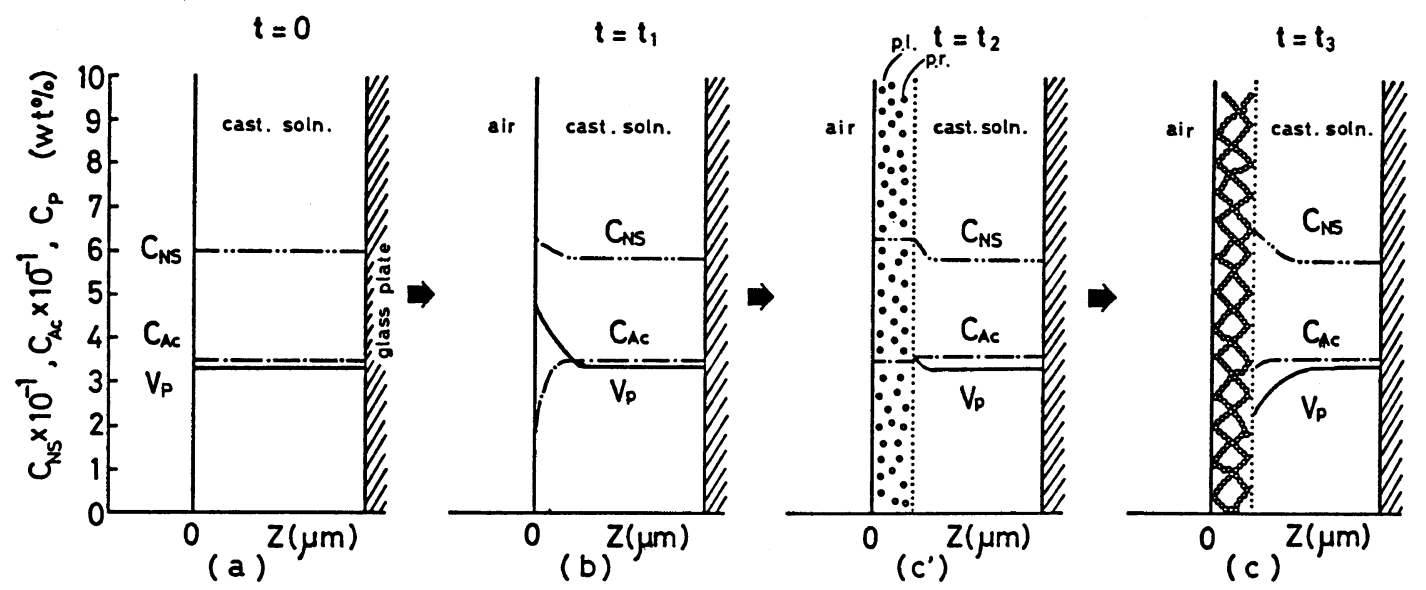

Figure 12. $Z$ dependence of the concentrations of cellulose acetate $\left(V_{\mathrm{p}}\right)$, acetone $\left(C_{\mathrm{Ac}}\right)$, and non-solvent $\left(C_{\mathrm{NS}}\right)$ in the polymer-lean phase and casting solution at time $t$ : (a), immediately after casting on the glass plate $(t=0)$; (b), at an arbitrary time $\left(t=t_{1}\right)$ before the phase separation; ( $\left.\mathrm{c}^{\prime}\right)$, immediately after the occurrence of the phase separation $\left(t=t_{2}\right)$ near the boundary of the casting solution; (c), after mixing of the polymer-lean phase and casting solution $\left(t=t_{3}\right)$.

stantaneously with the coagulation solution. The composition of the coagulation solution after mixing can be demonstrated in Figure $11 \mathrm{c}$.

$V_{\mathrm{p}}$ of the casting solution increases with time at the same $Z$ because the total flux of water and ammonia from the casting solution is always larger than that of acetone from the coagulation solution. The time when the phase separation occurs is controlled mainly by $C_{\mathrm{Am}}$. The phase separation proceeds from the front surface $(Z=0 \mu \mathrm{m})$ to the back surface $(Z=$ $120 \mu \mathrm{m}$ in the case of RC membrane) with time. With an increase in $Z$ the initiation time of phase separation becomes long and then phase separation occurs at a higher value of $V_{\mathrm{p}}$. The prediction derived from the pore characteristics for RC membrane that $V_{\mathrm{p}}$ must increase with $Z$ is confirmed by the data on molecular transportation. Then, we can conclude definitely that when the total flux of water and ammonia from the casting solution to the coagulation solution is always larger than that of acetone from the coagulation solution to the casting solution, the mean pore radius and porosity decrease with increasing $Z$ as in the case of a RC membrane.
The characteristics of the phase separation in CA membrane formation have been disclosed already by Kamide and Manabe et al. ${ }^{6}$ On the basis of the composition data of the polymer-lean phase and vapor pressure of the component solvents at $298 \mathrm{~K}$, we can estimate the dependence of $V_{\mathrm{p}}$ on $Z$ for CA membrane.

Figure 12 demonstrates the $Z$ dependence of the concentrations of cellulose acetate $\left(V_{\mathrm{p}}\right)$, acetone $\left(C_{\mathrm{Ac}}\right)$, and non-solvents $\left(C_{\mathrm{NS}}\right)$ in the polymer-lean phase and the casting solution at a given time $t$. Here, the non-solvents are methanol, calcium chloride, water, and cyclohexanol. Until $t_{1}$, no phase separation occurs (Figure 12b). Acetone (a good solvent in this case) evaporates from the casting solution resulting in an increase in $V_{\mathrm{p}}$ and $C_{\mathrm{NS}}$, which is pronounced at the interfacial boundary between the casting solution and air and $V_{\mathrm{p}}$ at $t=t_{1}$ is larger than that at $t=0$. The increase gives rise to the phase separation at $t=t_{2}$ (Figure 12c'). After the phase separation occurs, the polymer-rich phase generates many fine particles (the primary particles ${ }^{4}$ ) and these particles finally contact each other. The solvent molecules in the polymer-lean phase mix with the casting solution at $t=t_{3}$ and then the 
profile of Figure $12 \mathrm{c}$ is obtained. This mixing initiates the decrease in $V_{\mathrm{p}}$ of the casting solution. Since the volume of the polymer lean phase increases with phase separation, $V_{\mathrm{p}}$ decreases with time. This is the case for the CA membrane and $V_{\mathrm{p}}$ decreases with $Z$. Therefore, the mean pore radius and porosity of the resultant CA membrane increase with $Z$, in contrast to the case of the RC membrane.

\section{REFERENCES}

1. R. E. Kesting and A. Manefee, Kolloid Z., 230, 241 (1969).

2. C. A. Smolders, "Ultrafiltration Membranes and Applications," A. R. Cooper, Ed., Plenum Press, New York, N. Y., 1980, p 161.
3. W. Pusch and A. Walch, J. Membrane Sci., 10, 325 (1982).

4. K. Kamide and S. Manabe, "Materials Science of Synthetic Membranes," D. R. Lloyd, Ed., American Chemical Society, Washington, D.C., 1985, p 197.

5. S. Manabe, Y. Shigemoto, and K. Kamide, Polym. J., 17, 775 (1985).

6. K. Kamide, S. Manabe, T. Matsui, S. Kajita, and T. Sakamoto, Kobunshi Ronbunshu, 34, 205 (1977).

7. S. Manabe, M. Iwata, and M. Inoue, Japanese Patent Application, 58-89625 (1983).

8. H. Iijima, M. Iwata, S. Manabe, and K. Kamide, Polym. J., to be submitted.

9. E. M. Washburn, C. J. West, N. E. Dorsey, F. R. Bichowsky, and M. D. Ring, Ed., "International Critical Tables," Vol. V, McGraw-Hill, New York and London, 1929, p 64.

10. Chemical Engineering Society Japan, Ed., "Bussei Jyosu," Vol. 3, Maruzen Co., Ltd., Tokyo, 1965, p 339. 